\title{
Prevalence of von Willebrand Disease among Nigerian Youths in Ibadan, South-Western Nigeria
}

\author{
Khadijah B. Shonde-Adebola ${ }^{1}$, Wuraola A. Shokunbi ${ }^{2}$, Mukhtar B. Adebola ${ }^{3}$ \\ ${ }^{1}$ Department of Haematology, Federal Medical Centre, Idi-Aba, Abeokuta, Nigeria \\ ${ }^{2}$ Department of Haematology, University College Hospital, University of Ibadan, Ibadan, Nigeria \\ ${ }^{3}$ Haematology Unit of the Department of Paediatrics, Federal Medical Centre, Idi-Aba, Abeokuta, Nigeria \\ Email: shondekaybee@gmail.com
}

How to cite this paper: Shonde-Adebola, K.B., Shokunbi, W.A. and Adebola, M.B. (2021) Prevalence of von Willebrand Disease among Nigerian Youths in Ibadan, SouthWestern Nigeria. Open Access Library Journal, 8: e7789.

https://doi.org/10.4236/oalib.1107789

Received: July 26, 2021

Accepted: August 16, 2021

Published: August 19, 2021

Copyright $\odot 2021$ by author(s) and Open Access Library Inc.

This work is licensed under the Creative Commons Attribution International License (CC BY 4.0).

http://creativecommons.org/licenses/by/4.0/

\section{(c) (i) Open Access}

\begin{abstract}
Introduction: Von Willebrand disease (VWD) is the commonest inherited bleeding disorder worldwide. The prevalence of VWD in African or Nigerian population is however not known. Objective: To determine the prevalence of VWD among apparently healthy youths in Ibadan, Southwestern Nigeria. Materials and Method: This was a descriptive, analytical, cross-sectional study, in which one hundred and eighty-two participants who met the inclusion criteria and who consented to partake in the study were recruited. Blood samples were taken for some hematological parameters. VWF:ag levels and factor VIII levels were determined by ELISA method using SPAN VWF and SPAN Factor VIII ELISA kits respectively. Results: Participants were aged 15 to 35 years with mean age of $22.96 \pm 4.22$ years. Majority (75.8\%) were in the age range 20 to 24 years. Ninety-six (52.7\%) of them were males while 86 (47.3\%) were females. The prevalence of VWD in this study was $2.2 \%$. The levels of VWF: Ag correlated positively well with FVIII antigen level $(r=0.487, p$ $=0.0001)$. Conclusion: The prevalence of VWD is $2.2 \%$ among apparently healthy youths in Ibadan, Southwestern Nigeria. There was a strong statistical relationship between the VWF:Ag level and FVIII antigen level $(\mathrm{p}=0.0001)$.
\end{abstract}

\section{Subject Areas}

Hematology

\section{Keywords}

Von Willebrand Disease, Von Willebrand Factor, Factor VIII Antigen, Bleeding Disorder, Prevalence 


\section{Introduction}

Von Willebrand disease (VWD) is the most common inherited bleeding disorder worldwide with an overall prevalence of $1 \%$ and approximately $1.1 \%$ in the USA [1] [2]. VWD is due either to the deficiency or abnormal function of Von Willebrand factor (VWF) [3]. Its inheritance is usually autosomal dominant [2]. There are three main types of VWD, type 1 (quantitative partial deficiency), type 2 (functional abnormality; and has 4 sub types $2 \mathrm{~A}, 2 \mathrm{~B}, 2 \mathrm{~N}$ and $2 \mathrm{M}$ ) and type 3 (complete deficiency) Type 1 [4]. VWD accounts for $75 \%$ of cases in the Caucasians [2]. Von Willebrand factor (VWF) is a large adhesive protein encoded by a gene on chromosome 12 [5]. It is produced predominantly in vascular endothelial cells but also in megakaryocytes and circulates in the plasma as series of heterogeneous multimers. The VWF multimers may be released at a steady state from the endothelial cells (constitutive pathway) or stored prior to release in the Weibel-Palade bodies of endothelial cells (regulated pathway). Platelet VWF does not contribute significantly to plasma VWF and is stored in the alpha granules of platelets prior to release after platelet activation [6]. VWF has two major functions in haemostasis. Firstly, it is essential for platelet-subendothelium adhesion and platelet-to-platelet interactions as well as platelet aggregation in vessels with high shear stress [7]. Secondly, it is the carrier molecule for coagulation factor VIII (FVIII) in plasma, protecting it from proteolytic degradation, prolonging its half-life in circulation and efficiently localizing it to the site of vascular injury [8]. The plasma levels of VWF vary significantly within and between individuals. These variations have been associated with $\mathrm{ABO}$ blood type, race, estrogen levels, age and stress. In particular, ABO blood type exerts a major effect on plasma VWF levels. Studies have demonstrated that individuals carrying one $\mathrm{O}$ allele $(\mathrm{AO}$ and $\mathrm{BO}$ ) have significantly lower plasma levels of VWF and factor VIII than those carrying no $\mathrm{O}$ allele (AA, $\mathrm{AB}$ and $\mathrm{BB}$ ) [9]. This makes the diagnosis of VWD difficult in that, many individuals especially those with blood group O, who may lack the VWF gene mutation but have modestly low levels of VWF and mild or questionable bleeding tendencies, may be wrongly diagnosed with type I VWD; hence definitive diagnosis requires the presence of mutation in the VWF gene in conjunction with strong personal or familial history of bleeding symptoms [10]. Chronic elevation of VWF is part of acute phase response to injury, inflammation, neoplasm, or pregnancy. These responses may however reach pathological expression in being associated with an increased risk of thrombosis [11]. VWF level increases with age, rising by an average of 17 IU/dL per decade increase in age, so that by adulthood most patients especially those with type 1 VWD tend to become asymptomatic, hence the preference for youths in this study. Patients with VWD, typically present with mucous membrane bleeding (e.g. epistaxis and menorrhagia), excessive blood loss from superficial cuts and abrasions, and operative and post-traumatic haemorrhage. The severity of bleeding is variable in the different types of VWD, depending on the mutation type and epigenetic effects such as $\mathrm{ABO}$ blood group. Haemarthrosis 
and muscle haematomas are rare, except in type 3 disease [12]. The treatment of bleeding in VWD involves the use of Desmopressin and plasma-derived VWF concentrates and variety of adjunctive agents. A recombinant VWF concentrate (Vonvendi) which has completed clinical trial evaluation and has been approved by the United States food and drug Administration (FDA) on December 8, 2015 for adults 18 years and older who have VWD [13]. It has shown an excellent haemostatic efficacy and safety [13].

\section{Objective}

The prevalence of VWD in the African or Nigerian population is not known and therefore this study was conducted to determine the prevalence of von Willebrand Disease (VWD) among apparently healthy youths in Ibadan, Southwest Nigeria.

\section{Materials and Methods}

This was a descriptive, analytical, cross-sectional study. The study population consisted of apparently healthy youths, who consented to participate in the study. The criterion for their inclusion in the study, was apparently healthy youths aged $15-35$ years, who willingly gave informed consent to take part in the study. Exclusion criteria were persons below 15 years or above 35 years, acute illnesses e.g. malaria, chronic illnesses e.g. hypertension, diabetes, sickle cell disease, etc who may have high VWF levels as part of the disease process ((VWF being an acute phase reactant), medications e.g. oral contraceptive pills (oestrogens for example stimulates VWF production) and pregnant females (VWF increases significantly in pregnancy).

Sample Collection: Participants were made comfortable in a sitting position. The tourniquet was gently applied just above the antecubital fossa and the antecubital fossa was cleaned using a 70\% alcohol cotton wool. Then, seven milliliters ( $\mathrm{ml}$ ) of venous blood sample was collected by a free flowing, non-traumatic procedure using $21 \mathrm{G}$ needle. The blood drawn was distributed into two sample bottles as follows; (i) $4.5 \mathrm{mls}$ into evacuated plastic tubes containing $0.5 \mathrm{ml}$ of 32 $\mathrm{g} / \mathrm{L}$ of trisodium citrate anticoagulant. Platelet poor plasma was obtained by centrifuging at 3000 revolutions per minute for 15 minutes within 2 hours of sample collection using laboratory bench centrifuge (Universal 32, Hettich Zentrifugen, Germany). Plasma was stored at $-40^{\circ} \mathrm{C}$ until assayed (stable for 3 months without significant loss of haemostatic activities). Plasma samples were assayed for VWF:ag levels and coagulant factor VIII by ELISA method using SPAN VWF ELISA Assay Kit and SPAN Factor VIII ELISA Assay Kit respectively. (ii) $2.5 \mathrm{mls}$ was put into universal bottle for $\mathrm{ABO}$ blood grouping.

Data collection: data was obtained by use of an interviewer administered questionnaire to obtain information on the demographic and biological variables from all consenting participants. The information was entered into statistical software-Statistical Package for Social Sciences (SPSS) version 22 manufactured 
by IBM. The data was analyzed using descriptive statistics. The association between categorical variables was determined for statistical significance using the chi-square test while for continuous variables the significance of the difference between any two mean values was tested using student $t$ test, with level of significance set at $\mathrm{p}$-value $<0.05$.

\section{Results}

A total number of 182 apparently healthy youths, aged 15 to 35 years were recruited into the study. The mean age of the subjects was $22.96 \pm 4.22$. Majority (75.8\%) of them were in the age range 20 to 24 years. Ninety-six of these subjects (52.7\%) were males while eighty-six (47.3\%) were females. The prevalence of VWD among healthy youths in Ibadan was $2.2 \%$, based on the identification of 4 cases of VWD (Table 1) out of 182 participants. The mean VWF:Ag was $103.2 \pm$ $52.7 \mathrm{IU} / \mathrm{dL}$ and the mean VWF:Ag based on blood group, showed the lowest mean VWF:Ag value in subjects with group O $(87.1 \pm 39.9)$ as shown in Table 2. The mean FVIII level observed was $100.5 \pm 46.7 \mathrm{IU} / \mathrm{dL}$. There was a strong correlation between VWF:Ag and FVIII antigen level $(\mathrm{r}=0.487, \mathrm{p}=0.0001)$ as shown in Table 3.

Table 1. Laboratory findings and bleeding history in the subjects with VWD.

\begin{tabular}{|c|c|c|c|c|c|c|c|c|c|c|}
\hline $\mathrm{S} / \mathrm{N}$ & $\begin{array}{l}\text { Age } \\
\text { (yrs) }\end{array}$ & Sex & $\begin{array}{c}\text { Site of } \\
\text { bleeding }\end{array}$ & $\begin{array}{c}\text { Family } \\
\text { history } \\
\text { of } \\
\text { bleeding }\end{array}$ & $\begin{array}{l}\text { Blood } \\
\text { group }\end{array}$ & $\begin{array}{c}\mathrm{PT}(\mathrm{Sec}) \\
/ \mathrm{INR}\end{array}$ & $\begin{array}{c}\text { APTT } \\
(\mathrm{Sec})\end{array}$ & $\begin{array}{c}\text { Platelet } \\
\text { count } / \mathrm{m} \\
\mathrm{m}^{3}\end{array}$ & $\begin{array}{l}\text { VWF } \\
\text { (IU/dL) }\end{array}$ & $\begin{array}{c}\text { FVIII } \\
(\mathrm{IU} / \mathrm{dL})\end{array}$ \\
\hline 1 & 21 & $\mathrm{~F}$ & $\begin{array}{c}\text { Gum \& } \\
\text { Nose }\end{array}$ & Nil & $\mathrm{O}$ & $13 / 0.9$ & 32 & 79000 & 21 & 69 \\
\hline 2 & 30 & $\mathrm{M}$ & Gum & Nil & B & $13 / 0.9$ & 39 & 135000 & 37 & 63 \\
\hline 3 & 23 & $\mathrm{M}$ & $\begin{array}{c}\text { Gum \& } \\
\text { Nose }\end{array}$ & Mother & A & $15 / 1.1$ & 45 & 215000 & 39 & 21 \\
\hline 4 & 22 & $\mathrm{~F}$ & $\begin{array}{c}\text { Gum \& } \\
\text { Nose }\end{array}$ & Nil & $\mathrm{O}$ & $14 / 1.0$ & 39 & 446000 & 31 & 40 \\
\hline
\end{tabular}

Table 2. Mean VWF of study participants in relation to their blood groups.

\begin{tabular}{cc}
\hline Characteristics & Mean \pm SD \\
\hline VWF (overall) $(\mathrm{n}=182)$ & $103.2 \pm 52.7$ \\
VWF (in blood group O) $(\mathrm{n}=103)$ & $87.1 \pm 39.9$ \\
VWF (in blood group AB) $(\mathrm{n}=2)$ & $87.5 \pm 37.5$ \\
VWF (in blood group A) $(\mathrm{n}=37)$ & $116.5 \pm 59.9$ \\
$\operatorname{VWF}($ in blood group B) $(\mathrm{n}=40)$ & $133.0 \pm 60.0$ \\
\hline
\end{tabular}


Table 3. Mean value of VWF of the study participants in relation with the FVIII levels and their blood groups.

\begin{tabular}{|c|c|c|c|c|c|c|c|}
\hline Profile & $\begin{array}{l}\text { Low VWF } \\
(<50 \mathrm{IU}) \\
\mathrm{n}(\%)\end{array}$ & $\begin{array}{c}\text { Mean } \\
\mathrm{VWF} \pm \mathrm{SD}\end{array}$ & $\begin{array}{c}\text { Normal VWF } \\
(50-200 \text { IU) } \\
n(\%)\end{array}$ & $\begin{array}{c}\text { Mean } \\
\mathrm{VWF} \pm \mathrm{SD}\end{array}$ & $\begin{array}{l}\text { High VWF } \\
(>200 \mathrm{IU}) \\
\mathrm{n}(\%)\end{array}$ & $\begin{array}{c}\text { Mean } \\
\mathrm{VWF} \pm \mathrm{SD}\end{array}$ & $\mathrm{P}$-value \\
\hline \multicolumn{8}{|l|}{ Factor VIII } \\
\hline$<50$ & $12(63.2)$ & $32.4 \pm 11.1$ & $9(6.0)$ & $71.6 \pm 17.9$ & $0(0.0)$ & 0 & \multirow{4}{*}{0.0001} \\
\hline $50-150$ & $7(36.8)$ & $40.9 \pm 8.6$ & $125(82.8)$ & $99.8 \pm 37.5$ & $9(75.0)$ & $236.3 \pm 0$ & \\
\hline$>150$ & $0(0.0)$ & 0 & $17(11.3)$ & $128.4 \pm 34.3$ & $3(25.0)$ & $213.7 \pm 15.0$ & \\
\hline Total & $19(100)$ & $37.4 \pm 10.9$ & $151(100)$ & $101.3 \pm 37.9$ & $12(100)$ & $230.7 \pm 24.3$ & \\
\hline \multicolumn{8}{|c|}{$\mathrm{ABO}$ blood group } \\
\hline $\mathrm{O}$ & $13(68.4)$ & $36.9 \pm 11.6$ & 89 (58.9) & $92.9 \pm 34.5$ & $1(8.3)$ & $231.0 \pm 0$ & \multirow{5}{*}{0.0001} \\
\hline A & $4(21.1)$ & $41.0 \pm 11.9$ & $29(19.2)$ & $108.5 \pm 33.8$ & $4(33.3)$ & $249.5 \pm 23.7$ & \\
\hline B & $2(10.5)$ & $33.5 \pm 4.9$ & $31(20.5)$ & $119.8 \pm 44.7$ & $7(58.3)$ & $219.3 \pm 20.7$ & \\
\hline $\mathrm{AB}$ & $0(0.0)$ & 0 & $2(1.3)$ & $87.5 \pm 37.5$ & $0(0.0)$ & 0 & \\
\hline Total & $19(100)$ & $37.4 \pm 10.9$ & $151(100)$ & $101.3 \pm 37.9$ & $12(100)$ & $230.7 \pm 24.3$ & \\
\hline \multicolumn{8}{|c|}{ Rh Blood Group } \\
\hline Positive & $18(94.7)$ & $38.9 \pm 8.9$ & $139(92.1)$ & $100.3 \pm 27.5$ & $12(100)$ & $230.7 \pm 24.3$ & \multirow{3}{*}{0.859} \\
\hline Negative & $1(5.3)$ & $10.0 \pm 0$ & $12(7.9)$ & $113.7 \pm 41.9$ & $0(0.0)$ & 0 & \\
\hline Total & $19(100)$ & $37.4 \pm 10.9$ & $151(100)$ & $101.3 \pm 37.9$ & $12(100)$ & $230.7 \pm 24.3$ & \\
\hline
\end{tabular}

\section{Discussion}

The prevalence of VWD among apparently healthy Nigerian youths in this study was $2.2 \%$. Four participants had VWD out of 182 healthy study participants. This prevalence rate $(2.2 \%)$ is higher than the calculated VWD prevalence of $1.15 \%$ (14 of the 1218 school children of the Veneto region of Northern Italy) found in the study by Rodeghiego et al. 1987 [14] as well as the worldwide prevalence of $1 \%$ [1]. This may be due to the relatively smaller sample size in this study. There were equal numbers of both male and female among the 4 cases identified with VWD in this study. This is in agreement with the general observation that VWD affect both sexes equally [15].

In the study by Rodeghiero et al. (1987), there were more females $(\mathrm{n}=10)$ than males $(n=4)$ among the 14 cases of VWD identified which gave a lower M:F of 1:2.5 [14]. All the 4 cases in this study had positive history of mucosal bleeding in the form of epistaxis (in 3/4) and gum bleeding (in all 4), consistent with the commonest bleeding site in VWD. However, a family history of bleeding was positive only in one of the 4 (25\%) cases similar to the observation in the study by Sandhu et al. (2012) [16] who obtained a positive family history in $28 \%$ of the cases studied [16]. In the study by Rodeghiero et al. (1987), all the 14 cases out of 1218 children had a positive family history [14].

VWF:Ag levels in these 4 cases ranged between 21 and $39 \mathrm{IU} / \mathrm{dL}$. Lower 
VWF:Ag values were observed in those with blood group $\mathrm{O}$ than non-O among these 4 cases. Two of them were of the blood group $O$ type, and one case each had blood group A and blood group B. This is similar to the observation in the study by Rodeghiero et al. (1987) [14], in which there were also higher frequency of blood group O [ 9 of 14] with blood group A in 4 of 14 and 1 of 14 being blood group B [14].

Two out of the 4 cases of VWD in this study also had low FVIII level $(<50$ IU/dL). This is similar to the study by Rodeghiero et al. who observed low FVIII $<50 \mathrm{IU} / \mathrm{dL}$ in 7 of the 14 cases VWD [14]. The mean FVIII in the four cases was 48.25 IU/dL which is slightly lower than the mean FVIII of $62 \mathrm{IU} / \mathrm{dL}$ found in 25 of 85 cases (16\%) studied by Sandhu et al. (2012) [16]. The diagnosis of VWD involves presence or absence of clinical symptoms including excessive mucocutaneous bleeding in conjuction with coagulation studies consistent with quantitative and qualitative VWF abnormalities and possibly a family history of the disease. Laboratory tests for assessment of VWD should include bleeding time (BT), VWF:Ag assay, FVIII assay, VWF:RCo, RIPA, VWF multimer analysis and VWF:CB assay. However, due to limited resources, only FVIII assay, VWF antigen assay, PT, APTT and platelet count were performed. The diagnosis of VWD in these 4 cases was based on the presence of positive history of bleeding, with or without a family history of bleeding, low level of VWF, low or normal FVIII level, normal prothrombin time, normal or prolonged APTT, and normal or low platelet counts. This study has provided evidence of low VWF:Ag, low or boarder line FVIII level and presence of recurrent mucocutaneous bleeding in these 4 subjects (Table 1).

It is well known that Factor VIII level vary significantly with VWF:Ag level. This is because VWF is the carrier molecule for coagulation factor VIII in plasma [9]. This was well demonstrated in this study in that a significant percentage of the study subjects with low FVIII (35\%) and high FVIII (24\%) had correspondingly low and high levels of VWF:Ag respectively p-value; $<0.0001$ (Table 3).

The VWF:Ag level in this study varied with the ABO blood group. The overall mean VWF:Ag level in all the study subjects was $103.2 \mathrm{IU} / \mathrm{dL}$. However, the blood group specific mean VWF:Ag levels varied significantly. Subjects with blood group O had the lowest mean (87.1 IU/dL) compared with that of non-O groups, with blood group B having the highest mean VWF:Ag (133IU/dL) followed by group A (116.5 IU/dL). Those with group AB had mean VWF:Ag of $87.5 \mathrm{IU} / \mathrm{dl}$, which is just a little higher than those with blood group $\mathrm{O}$ [i.e mean VWF in $\mathrm{B}>\mathrm{A}>\mathrm{AB}>\mathrm{O}$ ], see Table 2. This observation was similar to the findings in the study by Gill and colleagues (1987) who reported lowest mean VWF:Ag in blood group O (74.8 IU/dL) except the fact that , that study found the highest mean VWF:Ag (123 IU/dl) in group AB [9]. In a study by Akpan and Essien (2016) in Uyo, Nigeria among a cohort of 100 blood donors, it was observed that blood group B subjects had the highest mean VWF:Ag (217.6 IU/dL), which is similar, though higher than what was observed in this study [17]. 


\section{Conclusion}

The prevalence of VWD among Nigerian youth as observed in this study was $2.2 \%$, with an equal male to female distribution. VWF:Ag level correlated well with FVIII levels. This study also showed variation in plasma level of VWF:Ag with different $\mathrm{ABO}$ blood group antigens with individuals with blood group $\mathrm{O}$ having the lowest mean VWF level and group B having the highest mean VWF level.

\section{Acknowledgements}

We thank the resident doctors in the Department of Haematology, University College Hospital (UCH), Ibadan, Nigeria for their involvement in the collection of blood samples from the study participants. We also thank Mr Abdulssattar Olomu of the research laboratory of Haematology department as well as doctors Ayoade and Sonuga of the ELISA laboratory of the department of Chemical pathology UCH Ibadan Nigeria, who were involved in the processing of the blood samples collected from study participants.

\section{Conflicts of Interest}

The authors declare no conflicts of interest.

\section{References}

[1] Borhany, M., et al. (2011) Clinical Features and Types of Von Willebrand Disease in Karachi. Clinical and Applied Thrombosis/ Hemostasis, 17, E102-E105.

[2] Federici, A.B. (2006) Diagnosis of Inherited von Willebrand Disease: A Clinical Perspective. Seminars in Thrombosis and Hemostasis, 32, 555-565. https://doi.org/10.1055/s-2006-949661

[3] Mohlke, K.L. and Ginsburg, D. (1997) Von Willebrand Disease and Quantitative Deficiency of Von Willebrand Factor. Journal of Laboratory and Clinical Medicine, 130, 252-261. https://doi.org/10.1016/S0022-2143(97)90019-6

[4] Sadler, J.E., Budde, U. and Eienboom, J.C. (2006) Update on the Pathophysiology and Classification of Von Willebrand Disease: A Report of the Subcommittee on Von Willebrand Factor. Journal of Thrombosis and Haemostasis, 4, 2103-2114. https://doi.org/10.1111/j.1538-7836.2006.02146.x

[5] Ginsburg, D., et al. (1985) Human Von Willebrand Factor (vWF): Isolation of Complementary DNA (cDNA) Clones and Chromosomal Localization. Science, 228, 1401-1406. https://doi.org/10.1126/science. 3874428

[6] deWit, T.R. and vanMourik, J.A. (2001) Biosynthesis, Processing and Secretion of von Willebrand Factor: Biological Implications. Best Practice \& Research Clinical Haematology, 14, 241-255. https://doi.org/10.1053/beha.2001.0132

[7] Ruggeri, Z.M., Ware, J. and Ginsburg, D. (2003) Von Willebrand Factor. In: Loscalzo, J. and AI, S., Eds., Thrombosis and Haemorrhage, 3rd Edition, Philadelphia Lippincott, Williams \& Wilkins, Philadelphia, 246.

[8] Sadler, J.E. (1998) Biochemistry and Genetics of von Willebrand Factor. Annual Review of Biochemistry, 67, 395-424.

https://doi.org/10.1146/annurev.biochem.67.1.395 
[9] Gill, J.C., Endres-Brooks, J., Bauer, P.J., Marks, W.J. and Montgomery, R.R. (1987) The Effect of ABO Blood Group on the Diagnosis of von Willebrand Disease. Blood, 69, 1691-1695. https://doi.org/10.1182/blood.V69.6.1691.1691

[10] Nitu-Whalley, I.C. and Lee, C.A. (2000) Type 1 von Willebrand Disease: A Clinical Retrospective Study of the Diagnosis, the Influence of ABO Blood Group and the Role of Bleeding History. British Journal of Haematology, 108, 259-264. https://doi.org/10.1046/j.1365-2141.2000.01830.x

[11] Van Loon, J.E., Kavousi, M., Felix, J.F., Leebeek, F.W., Hofman, A., Witterman, J.C., et al. (2012) Von Willebrand Factor Plasma Levels, Genetic Variations and Coronary Heart Dissease in Older Popoulation. Journal of Thrombosis and Haemostasis, 10, 1262-1269. https://doi.org/10.1111/j.1538-7836.2012.04771.x

[12] Nosek-Cenkowska, B., Cheang, M.S. and Pizzi, N.J. (1991) Bleeding/Bruising Symptomatology in Children with and without Bleeding Disorders. Thromb Haemost, 65, 237-241. https://doi.org/10.1055/s-0038-1647491

[13] CenterWatch. (2015) Vonvendi: Von Willebrand Factor (Recombinant). https://www.centerwatch.com/

[14] Rodeghiero, F. and Castaman, G. and Dini, E. (1987) Epidemiological Investigation of the Prevalence of von Willebrand's Disease. Blood, 69, 454-459. https://doi.org/10.1182/blood.V69.2.454.454

[15] Bloom, A.L. (1991) Von Willebrand Factor: Clinical Features of Inherited and Acquired Disorders. Mayo Clinic Proceedings, 66, 743. https://doi.org/10.1016/S0025-6196(12)62088-6

[16] Sandhu, M.K., Shah, S., Jacoby, S.H. and Cohen, A.J. (2012) Patterns of Bleeding in Males with von Willebrand Disease. Blood, 120, 1129. https://doi.org/10.1182/blood.V120.21.1129.1129

[17] Akpan, I.S. and Essien, E.M. (2016) ABO Blood Group Status and von Willebrand Factor Antigen Levels in a Cohort of 100 Blood Donors in an African Population. International Journal of Biomedical Research, 7, 219-222. 